\title{
Understanding the Dynamics of Friendship Formation among High school Adolescent: Indigenous Psychology Approach
}

\author{
Banyu Wicaksono ${ }^{1}$, Maria Goretti Adiyanti ${ }^{2}$ \\ ${ }^{1}$ Department of Psychology, Universitas Negeri Yogyakarta, \\ Jl. Colombo No. 1 Karang Malang Sleman, Yogyakarta \\ ${ }^{2}$ Faculty of Psychology Universitas Gadjah Mada, \\ Jl. Humaniora 1 Bulaksumur, Sleman, Yogyakarta \\ 1banyuwicaksono@uny.ac.id, ${ }^{2}$ adiyanti_psy@ugm.ac.id
}

\begin{abstract}
How friendship between adolescent peers was formed is yet to be understood clearly. Whereas number of studies has clearly linked quality of friendship to various adaptive ability, school performance, and academic achievements. This study attempted to understand the dynamics of friendship formation in sample Javanese adolescents using indigenous psychology as its' paradigm. Data was obtained from 120 respondents, (82 Girls, and 38 Boys) using open-ended questionnaire, which asks about how friendship between the respondent and their close friend(s) was formed. Data was analyzed using thematic analysis to identify themes and subthemes that indicates how friendship was formed. The result showed that there are two major theme that emerges in the beginning of friendship formation followed by other qualities related to it. This study reveals one more important aspect to be considered in understanding friendship formation between adolescents and their close friends.
\end{abstract}

Keywords: Friendship; Friendship Formation; Adolescent

\section{Introduction}

Friendship is a form of human activity that is important and full of meaning (Caroline, 1993). The phenomenon of friendship is a subject of interest for social psychologist to understand how a stranger transform into having a significant and influential role in one's life.

Friendship is a social phenomenon that has been existed in one's life since childhood. However, the importance of close friends as a significant person becomes increasingly pronounced as a person transitioned into adolescence, shifting parent's role as primary source of emotional support (Collins \& Steinberg, 2006; Brown \& Klute, 2003). This is transition was also strengthened by the fact that adolescents spent at least a third of their time a day with his friends, primarily in school
(Hartup \& Stevens, 1997). Number of research has shown that close friend plays a crucial role as emotional support for adolescents, and has been linked good friendship quality to better school performance, academic achievements, and adaptive ability (Gallardo, Barrasa, \& Guevara-Viejo, 2016; Košir \& Tement, 2014; Lee, 2012; Wentzel \& Caldwell, 1997; Austin \& Draper, 1984).

In developmental perspective, friendship is something that evolves with time (Adams, Blieszner, \& de Vries, 2000). As a child, interpersonal relationships are highly characterized by a child's dependency on person older than them, especially parents and caregivers (Russel, Mize, \& K, 2002; Sullivan, 1953). At the beginning of adolescence, individuals began to form 
relationships with their peers in which qualities such as equality, togetherness, and mutual relations between the two parties starts to emerges. The world of peers in the view of adolescents is not just a substitute from home, the world of friends is a separate domain, community or society (Sullivan, 1953). A strong bond exists between its members, which is manifested in the form of rules and ethics in groups, moral climate, forming the context of one's own language, even determining what is appropriate and inappropriate (Jersild, 1965). This creates a bubble in which adolescents who are yet to form friendship with their peers will be vulnerable to falling into feelings of loneliness, and at risk of further distress (Hall \& Lindzey, 1978; Woodhouse, Dykas, \& Cassidy, 2012).

Furthermore, as a person enters adolescence they begin to perceive and understand abstract matter thanks to the cognitive transition into formal-operational stages (Rice \& Dolgin, 2008). This ability enables teenagers to perceive the emotions and thoughts of others. Thus, enabling them to understand abstract concepts such as trust, closeness, and relationship quality, all are essential component in forming deeper interpersonal relationship (Costa, 2004).

While friendship and its' properties and its' relation with various aspect in one's life has been properly defined, many basic and indepth aspects such as definition of friendship, process of which friendship was formed, and how it was ended is rarely investigated. This issue has been long noted by Jersildv (1965) which mentions the factors that attract two teenagers to come together to form friendly relations are very complex and not well understood. This remains true, even until today. One such explanation is that friendship was seen as a non-institutional, voluntary relationship and was not subject to institutional constraints that exists in family and neighbor relationship (Adams, Blieszner, \& de Vries, 2000). Therefore, the process of friendship formation, especially in adolescence, remains unclear. Our current study attempts to fill in that gap by exploring the dynamics of friendship formation in adolescents.

However, in investigating those issues, it is important to us to put cultural context into consideration. As Reis and colleagues (2000) noted that human behavior in the context of relations between individuals should not be separated from the context that surrounds the relationship. Due to cultural differences, the behavior of individuals from different regions will also have their own unique dynamics (Fiske, 1992).

To accommodate this, we will equip indigenous psychology as the main paradigm of our study. Kim, Yang, and Hwang (2006) explain that indigenous psychology is an approach whose context includes family, social, cultural and ecological, the contents of which are meaning, value and belief, are explicitly included in the research design. In other terms, indigenous psychology is a scientific perspective / paradigm designed to study human behavior and thought processes in an original way and not taken from other regions (Kim, Yang, \& Hwang, 2006; Kim \& Berry, 1993). This approach emphasizes efforts to gain a descriptive understanding of human function in a cultural context. Considering all of those factors and explanations, we formulate research question to be answered in this study "How is the process of friendship formation between adolescents and their close friends?"

\section{Methods}

\section{Research Design}

This is a qualitative exploratory study directed to explore and describe the dynamics of friendship formation in adolescent. Qualitative approach is the most suitable approach to answer the research question due to its' nature as an approach that enables the researcher to obtain descriptive data and to explore its' meaning (Creswell, 2009; Shaugnessy, Zechmeister, \& Zechmeister, 2012). 


\section{Dynamics of Friendship Formation ... \\ Banyu Wicaksono', Maria Goretti Adiyanti ${ }^{2}$}

\section{Participants}

Participants for this study were recruited through purposive sampling. Inclusion criteria for this research includes being an adolescent aged between 15 to 18 years, lives in Yogyakarta, has Javanese background, and has one or more close friend(s). The inclusion criteria were formulated based on the suggestion of Indigenous Psychology that researchers and respondents should come from the same cultural background to avoid misinterpretation due to cultural differences. A number of 120 respondents consisting of 82 Girls and 38 Boys participated in this study.

\section{Research Procedure and Data Collection Instruments}

Research permit was obtained from municipal government and school administrator prior to data collection. Then the data was collected at schools around Yogyakarta Region using survey questionnaire designed by B. W. The questionnaire consists of brief explanation regarding the study containing information of the aim of the research, the researcher, and confidentiality agreement. Informed consent was obtained from each of the students. Students whom agreed to participate then proceed to the first section of the questionnaire containing sociodemographic data to be filled in. Afterwards they fill answer five open ended question and seven fixed-response question that explores their relationship with their friends. One question was analyzed for this study, namely "Describe how your friendship began with your close friend(s)".

\section{Data Analysis}

Data obtained was then analyzed using inductive exploration using thematic analysis based on protocols developed by Braun and Clarke (2006). The data was digitized using Microsoft Word, printed, and cut into individual strips, each strip represents one participant. The researcher recruited three adolescent raters (N.A.B; A.K.W; A.W), aged between 18 to 19, has Javanese cultural background and lives in Yogyakarta. This was done to ensure the credibility of the analysis and complete interpretation of the data.

The rater and researcher (B.W.) first familiarize with the data by reading and rereading the data, as well as taking notes on initial codes that emerges from this process. Afterwards, the team was split into two group each independently coded all of the responses and comparing the resulting themes for discussion and resolving disagreements, to reach agreements on each code. Only then, the team collate all codes unto a final theme framework.

\section{Findings and Discussion}

Findings

Participant's Characteristics

Participants consisted of 33 boys $(31.67 \%)$ and 79 girls (68.33\%) Aged between 15 to 17 years $\left(M_{\text {Age: }}: 16.05\right)$, all of them are high-school students.

\section{Dynamics of Friendship Formation}

Several themes emerge from the data. Similarities seems to emerges as the initial point in which acquaintances starts to became friends. Similarity creates a common ground between the respondent and his friend. These common grounds facilitate further interpersonal interactions, such as talking, and having mutual understanding. Similarities serves as a starting point in which respondent and their friend starts to see each other more often, therefore it forms togetherness.

The second theme and process that emerges is togetherness, or the time spent together between friends. It appears as one of the main divides that separates friends and close friends. By spending time together, each party are able to evaluate each other and form trust. This enabled them to open-up with each other, sharing their problems, stories, or secrets that they did not tell to another friend. The disclosure allows better understanding of each other. Other deeper interpersonal interactions such as helping, caring, being "there" for their friends, being open, and cooperating with one another are also enabled by togetherness. 
However, togetherness also opens up opportunities for conflict between friends due to increased opportunities of friction between two individuals caused by the sheer amount of time spent together. The conflict also serves as a filter and rites of passage. Pair of friends that did not pass this will eventually drift away from each other and become regular friends. However, as they are able to make peace and resolves their conflict, this in turn will brought them closer. As bond

between friend become closer, close friendship is then formed.

As we analyze the data, we also interpret and analyse the data between boys and girls separately to reveal gender-specific dynamics. The result revealed different pattern of friendship formation between boys and girls. The dynamics of friendship formation in boys is represented in figure 1 . Whereas dynamics of friendship formation in girls is represented in figure 2 .

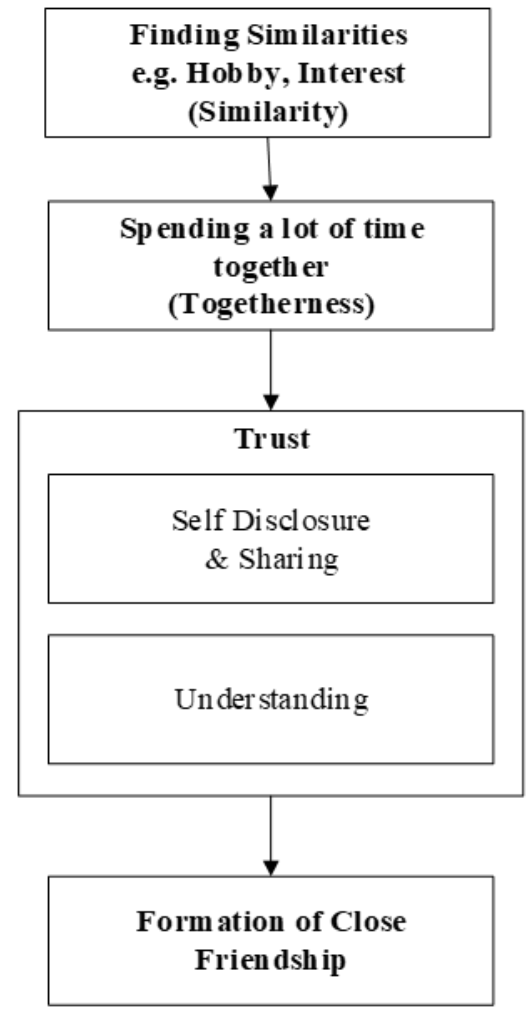

Figure 1. Formation of Friendship among Boys

Based on the analysis, boys have a rather straightforward pattern in friendship formation. Through togetherness they find trust that enables them to confide in their friends and form understanding that

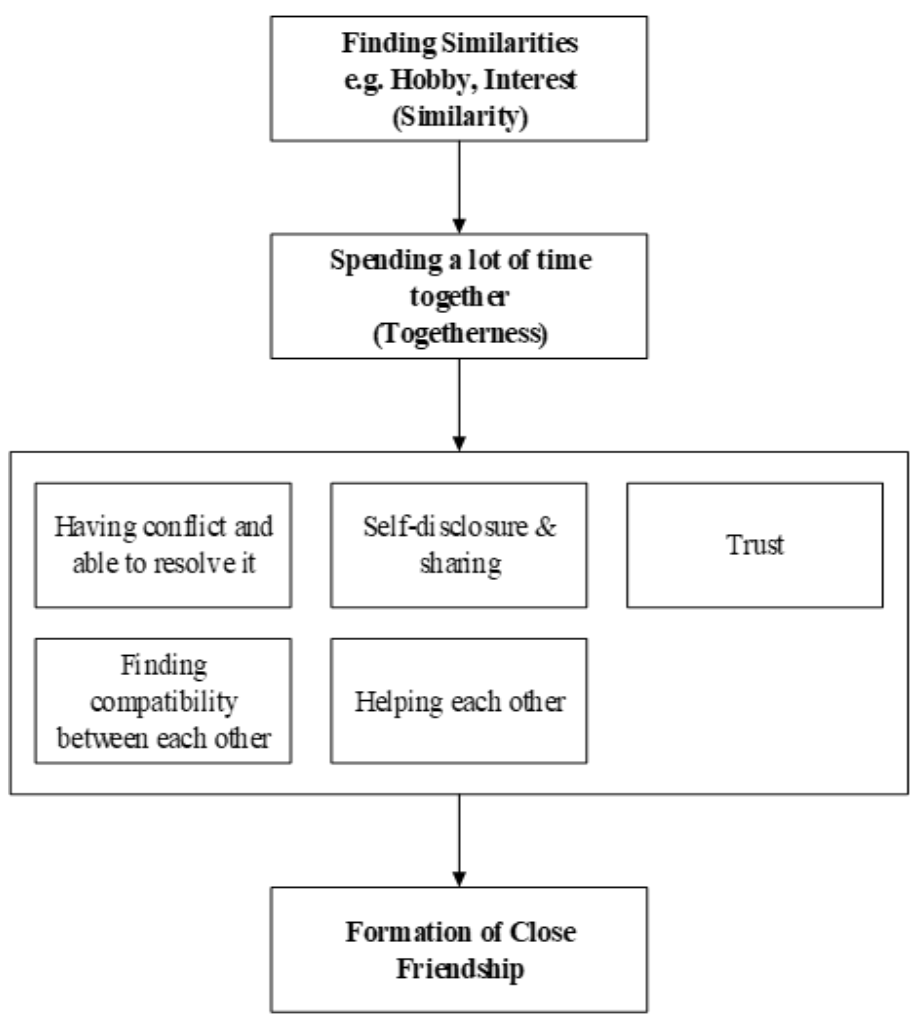

Figure 1. Formation of Friendship among Girls

strengthen their bonds, thus becoming close friends. Whereas girls have a more elaborate process that involves conflict resolution, finding compatibility, helping, self-disclosure and trust formation.

Table 1. Cross-tabulation of participant's gender with their close friend's gender

\begin{tabular}{lrrrrr}
\hline \multirow{3}{*}{ Close Friend's Gender } & \multicolumn{5}{c}{ Respondent's Gender } \\
\cline { 2 - 6 } & \multicolumn{3}{c}{ Boys } & \multicolumn{3}{c}{ Girls } \\
\cline { 2 - 6 } & $\mathbf{n}$ & $\mathbf{0}$ & $\mathbf{n}$ & $\mathbf{0}$ \\
\hline Boys & 24 & $77,42 \%$ & 11 & $14,47 \%$ \\
Girls & 7 & $22,58 \%$ & 65 & $85,53 \%$ \\
Total & $\mathbf{3 1}$ & $\mathbf{1 0 0} \%$ & $\mathbf{7 6}$ & $\mathbf{1 0 0 \%}$ \\
\hline
\end{tabular}


Further analysis on the demographic data and close ended questions also revealed that between boys and girls prefer friend with the same gender (see table 1) and same religion/belief (see table 2).

Table 2. Cross-tabulation of participant's religion with their close friend's religion

\begin{tabular}{|c|c|c|c|c|c|c|c|c|}
\hline \multirow{3}{*}{$\begin{array}{c}\text { Close } \\
\text { Friend's } \\
\text { Religion }\end{array}$} & \multicolumn{8}{|c|}{ Respondent's Religion } \\
\hline & \multicolumn{2}{|c|}{ Islam } & \multicolumn{2}{|c|}{ Catholic } & \multicolumn{2}{|c|}{ Protestant } & \multicolumn{2}{|c|}{ Hindu } \\
\hline & $\mathbf{n}$ & $\%$ & $\mathbf{n}$ & $\%$ & $n$ & $\%$ & $\mathrm{n}$ & $\%$ \\
\hline Islam & 88 & $95,65 \%$ & 3 & $60,00 \%$ & 3 & $50,00 \%$ & 1 & $100,00 \%$ \\
\hline Catholic & 2 & $2,17 \%$ & 1 & $20,00 \%$ & 2 & $33,33 \%$ & & $0,00 \%$ \\
\hline Protestant & 2 & $2,17 \%$ & 1 & $20,00 \%$ & 1 & $16,67 \%$ & & $0,00 \%$ \\
\hline Total & 92 & $100,00 \%$ & 5 & $100,00 \%$ & 6 & $100,00 \%$ & 1 & $100,00 \%$ \\
\hline
\end{tabular}

Discussion

The results above show that in general, friendship relations among adolescent respondents begin with the presence and similarity between the respondent and his close friend. The concept of togetherness tells of how two individuals spend more time together than they spend with other friends. Along with the time spent together, the two know each other more deeply. This then becomes the basis of friendship relations for the majority of respondents. Respondents spend more time with their close friends than ordinary friends. The difference in the quantity of time spent together becomes meaningful because understanding arises from the amount of time spent together, and this is the difference between an ordinary friend and a close friend. This result is also supported by previous research by Wicaksono, Adiwibowo, and Faturochman (2013) which states that the quantity of time spent together and the understanding that formed from it is the main reason an adolescents trusts their close friends.

The large amount of time the respondent spends with his close friend, indirectly, in addition to generating understanding, also brings up a condition where a friend is always at peace with his friend in both happy and difficult conditions. Characteristics exist in all of these conditions in line with the concept of social support as a function of friendship (Fehr, 2000). The analysis also shows that the characteristics there indicate interdependence in friendship relations.
The concept of togetherness and the quantity of time spent together as a consequence of the togetherness is in line with opinions and theories about relationship changes in adolescence where the role of parents decreases and the role of peers increases (Jersild, 1965). The discussion of the data above also shows that friendship relations are zones where adolescents can have their own autonomy without much influence from their parents.

The concept of similarity between the respondent and the respondent's close friend in terms of interests such as hobbies, favorite films, favorite books, or likes is in line with the concept of Fiske (2004) regarding the Relationship of Communal Sharing (CS). The similarity between the respondent and the respondent's close friend does not stop at the similarity of ideas, thoughts, behavior, ideal standards, and something that is liked / disliked, the similarity between the two includes the same gender, religion, and location. This is in line with the opinion of Kerchoff and Davis (1962) which states that there are several things that function as filters in interpersonal relations. Among them are gender, physical proximity, and religion. Respondents of this study tend to choose friends who have the same sex, the same religion, and are in the same location.

From the results of the discussion above, it can be concluded that the components of friendship relations revealed in this study are all connected to each other where all of them start from two interrelated things, togetherness and similarity. Both open 
the possibility of the emergence of forms and qualities of deeper relations. Togetherness brings understanding and quality there is equal in all situations. While understanding brings understanding so that individuals can be themselves in front of their friends. Meanwhile, the similarity between the individual and his friend becomes a communication lubricant between the two. By having a common ground, individuals can find topics and establish warm communication and build comfort based on similarity. Furthermore, together with trust, the warm communication that is established slowly develops into a process of selfdisclosure, and self-disclosure is what helps foster understanding between the two individuals. All of these components run harmoniously, together building a relationship where individuals can find people who are always there accompanying in every situation, know us closely so that they can understand and accept our strengths and weaknesses; a close friend. Discussion above can be summarized in the figure 3 .

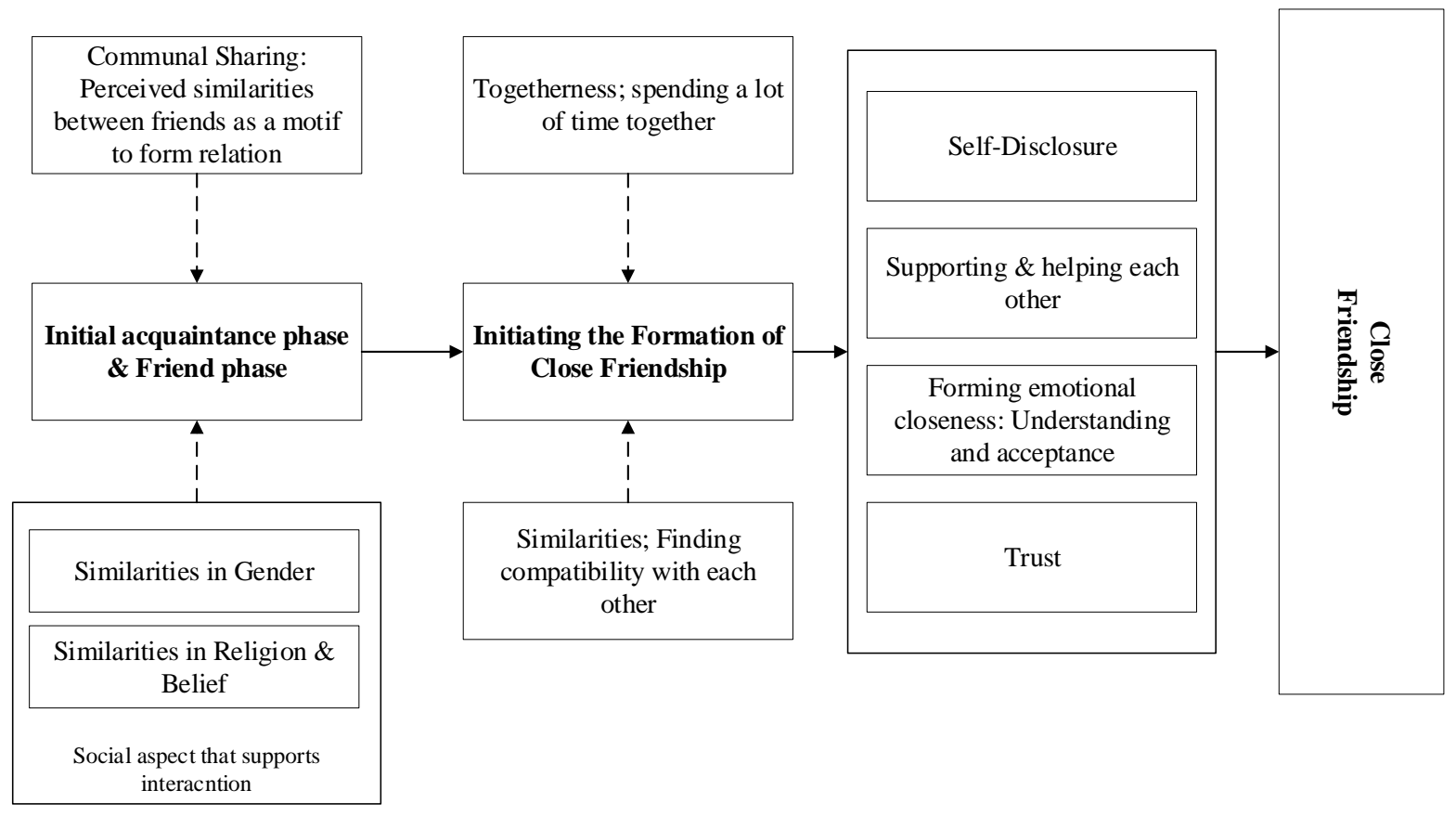

Figure 2. Dynamics of Friendship Formation in Adolescents

\section{Conclusion}

Close Friendship began with acquaintances finding similarities in each other. This encourage them to spend more time together, thus forming togetherness. As friends spent more time together, it allows them to understand their partner through self-disclosure, conflict resolution, and trust. Finally, these long chain of processes transforms acquaintance into someone who are always there for us, understands us and accepts who we are; a close friend.

\section{References}

Adams, R. G., Blieszner, R., \& de Vries, B. (2000). Definitions of friendship in the third age: age, gender, and study location effects. Journal of Aging Studies, 14(1), 117-133. doi:10.1016/S08904065(00)80019-5

Austin, A. M., \& Draper, D. C. (1984). The Relationship Among Peer Acceptance, Social Impact, and Academic Achievement in Middle Childhood. The American Educational Research 
Journal, 21(3), 597-604. doi:10.3102\%2F00028312021003597

Braun, V., \& Clarke, V. (2006). Using thematic analysis in psychology. Qualitative Research in Psychology, 3(2), 77-101. doi:10.1191/1478088706qp063oa

Brown, B. B., \& Klute, C. (2003). Friendships, cliques, and crowds. In G. R. Adams, \& M. D. Berzonsky (Eds.), Blackwell Handbook of Adolescence (pp. 330-348). Malden: Blackwell Publishing.

Caroline, H. A. (1993). Explorations of Close Friendships: A Concept Analysis. Archives of Psychiatric Nursing, 7(4), 236243. doi:10.1016/08839417(93)90032-R

Collins, W. A., \& Steinberg, L. (2006). Adolescent Development in Interpersonal Context. In W. Damon, \& R. Lerner (Eds.), Handbook of Child Psychology (6th ed.). New York: Wiley.

Costa, A. C. (2004). Trust. In C. Spielberger (Ed.), Encyclopedia of Applied Psychology (Vol. 3, pp. 611-620). Oxford: Elsevier Inc.

Creswell, J. W. (2009). Research Design: Qualitative, Quantitative, and Mixed Methods Approaches. Thousand Oaks, CA: Sage.

Fehr, B. (2000). The life cycle of friendship. In C. Hendrick, \& S. S. Hendrick (Eds.), Close Relationships: a Sourcebook (pp. 71-82). London: Sage Publications, Inc.

Fiske, A. P. (2004). Relational Models Theory 2.0. In H. Nick (Ed.), Relational Models Theory: A Contemporary Overview (pp. 325). Mahwah, NJ: Lawrence Erlbaum.

Gallardo, L., Barrasa, A., \& Guevara-Viejo, F. (2016). Positive peer relationships and academic achievement across early and midadolescence. Social Behavior and Personality: An international journal, 44(10), $\quad$ 1637-1648. doi:10.2224/sbp.2016.44.10.1637
Hall, C. S., \& Lindzey, G. (1978). Theories of Personality (3rd ed.). New York: John Wiley \& Sons.

Hartup, W., \& Stevens, N. (1997). Friendships and Adaptation in the Life Course. Psychological Bulletin, 121(3), 355-370. doi:10.1037/0033-2909.121.3.355

Jersild, A. T. (1965). The Psychology of Adolescence (2nd ed.). New York: The Macmillan Company.

Kerckhoff, A. C., \& Davis, K. E. (1962). Value Consensus and Need Complementarity in Mate Selection. American Sociological Review, 27(3), 295303. doi:10.2307/2089791

Kim, U., \& Berry, J. W. (1993). Indigenous Psychologies: Experience and Research in Cultural Context. Newbury Park, CA: Sage.

Kim, U., Yang, K. S., \& Hwang, K. K. (2006). Contributions to Indigenous and Cultural Psychology: Understanding People in Context. In U. Kim, K. S. Yang, \& K. K. Hwang (Eds.), Indigenous and Cultural Psychology: Understanding People in Context (pp. 326). New York: Springer.

Košir, K., \& Tement, S. (2014). Teacherstudent relationship and academic achievement: a cross-lagged longitudinal study on three different age groups. European Journal of Psychology of Education, 29(3), 409-428. doi:10.1007/s10212-013-0205-2

Lee, J. S. (2012). The effects of the teacherstudent relationship and academic press on student engagement and academic performance. International Journal of Educational Research, 53, 330340. doi:10.1016/j.ijer.2012.04.006

Reis, H. T., Collins, W. A., \& Berscheid, E. (2000). The relationship context of human behavior and development. Psychological Bulletin, 126(6), 844-872. doi:10.1037/0033-2909.126.6.844

Rice, F. P., \& Dolgin, K. G. (2008). The Adolescent: Development, Relationships, and 
Culture (10th ed.). Boston: Allyn and Bacon.

Russel, A., Mize, J., \& K, B. (2002). ParentChild Relationships. In P. K. Smith, \& C. H. Hart (Eds.), Blackwell Handbook of Childhood Social Development (pp. 205222). Oxford: Blackwell Publishers Ltd.

Shaugnessy, J. J., Zechmeister, E. B., \& Zechmeister, J. S. (2012). Research Methods in Psychology (9th ed.). New York: McGraw-Hill.

Sullivan, H. S. (1953). The Interpersonal Theory of Psychiatry. New York: W. W. Norton.

Wentzel, K. R., \& Caldwell, K. (1997). Friendships, peer acceptance, and group membership: relations to academic achievement in middle school. Child Development, 68(6), 1198$1209 . \quad$ doi:10.1111/j.14678624.1997.tb01994.x

Wicaksono, B., Adiwibowo, I. R., \& Faturochman. (2013). Adolescent Criteria for Trusting Their Close Friend. In R. Ismail, U. Kim, \& S. M. Iqbal (Eds.), International Conference of Asian Association of Indigenous and Cultural Psychology 2012 Proceeding (pp. 106-125). Perlis: Percetakan Madani.

Woodhouse, S. S., Dykas, M. J., \& Cassidy, J. (2012). Loneliness and Peer Relations in Adolescence. Social Development, 21(2), 273-293. doi:10.1111/j.14679507.2011.00611.x 